\title{
ОБОСНОВАНИЕ ПРИНЦИПОВ ПОСТРОЕНИЯ КАНАЛА УПРАВЛЕНИЯ, ТЕЛЕМЕТРИИ И ИНФОРМАЦИОННЫХ КАНАЛОВ МАЛОГАБАРИТНЫХ БПЛА
}

\section{JUSTIFICATION OF THE PRINCIPLES OF CONSTRUCTION OF THE CONTROL CHANNEL, TELEMETRY AND INFORMATION CHANNELS OF SMALL UAV}

V. Gel E. Evdokimov O. Senin

Summary. The article discusses the features and principles of constructing a control channel, telemetry and information channels of small-sized UAVs. In the course of the study, it was found that for organizing a control and telemetry channel for a small-sized UAV, it is advisable to use signals with direct spread spectrum, and for an information channel of a data reception and transmission system, digital methods based on the DVB digital television standard.

Keywords: information transmission, channel, digital method, reception.
Гель Валентин Эдуардович

К.в.н., дочент, полковник, Военная академия связи им. С.М. Буденного (2. Санкт-Петербург)

Евдокимов Евгений Викторович Майор, в/ч 02511

Сенин Олег Геннадьевич

Майор, адъюнкт, Военная академия связи им. С.М. Буденного (г. Санкт-Петербург) 9119536622@mail.ru

Аннотация. В статье рассмотрены особенности и принципы построения канала управления, телеметрии и информационных каналов малогабаритных БПЛА. В процессе исследования установлено, что для организации канала управления и телеметрии малогабаритным БПЛА целесообразно использовать сигналы с прямым расширением спектра, а для информационного канала системы приема и передачи данных цифровые методы на базе стандарта цифрового телевидения DVB-T2.

Ключевые слова: передача информации, канал, цифровой метод, прием.
Д остижения современной науки и техники в области авиастроения, вычислительной техники, радиоэлектроники и систем управления создали основу для реализации программ и проектов разработки беспилотных летательных аппаратов (БПЛА) различного целевого назначения. Более того, на сегодняшний день появились сферы применения, где БПЛА не имеют пилотируемой альтернативы [1].

Особое распространение в настоящее время получили малогабаритные БПЛА, рост интереса к которым в последние годы является результатом одновременного появления новых достижений в области миниатюризации компонентов летательных аппаратов и новых технических приемов применения таких аппаратов в контексте перспективных концепций информатизации.

При этом следует отметить, что современное технологическое развитие БПЛА в целом и малогабаритных в частности связано с использованием двух общих ресурсов - воздушного пространства и радиочастотного спектра [2]. Безаварийная эксплуатация БПЛА в значительной степени зависит от надежной работы радиотех- нических каналов связи между летательным аппаратом и станциями наземного управления, а также радиотехническими навигационными системами.

Система приема и передачи данных малогабаритных БПЛА предназначена для выполнения двух основных групп функций:

- обеспечение функционирования радиоканала управления и телеметрии для дистанционного автоматизированного управления БПЛА (канал управления);

- передача (прием) и обработка разведывательных данных системы оптико-электронной разведки БПЛА (информационный канал).

Основным фактором, ограничивающим функциональные возможности обоих каналов для малогабаритного БПЛА, являются достаточно жесткие габаритно-весовые ограничения. Ограничение на общий вес БПЛА составляет $1 \div 4$ кг, при максимально обозримом коэффициенте полезного действия специального оборудования общий вес бортовой подсистемы оптической разведки и передачи данных не должен превышать $0,15 \div 1$ кг. 
Таблица 1. Требования к телекоммуникационным линиям радиосвязи с БПЛА

\begin{tabular}{|l|l|l|}
\hline Назначение канала радиосвязи & $\begin{array}{l}\text { Канал управления БПЛА и передачи } \\
\text { телеметрической информации }\end{array}$ & $\begin{array}{l}\text { Канал передачи данных с полезной } \\
\text { нагрузкой (передача фото, видео данных) }\end{array}$ \\
\hline Вероятность битовой ошибки (BЕR) & Не более $10^{-7}$ & Не более $10^{-6}$ \\
\hline Скорость передачи данных & 56 Кбит/сек & 2-30 Мбит/сек \\
\hline $\begin{array}{l}\text { Направление передачи данных БПЛА— } \\
\text { НСУ }\end{array}$ & НСУ_БПЛА & БПЛА_НСУ \\
\hline
\end{tabular}

С учетом вышеизложенного, не подлежит сомнению тот факт, что построение канала управления, который будет характеризоваться высокой скрытностью и помехозащищенностью, а также информационного канала, обеспечивающего максимизацию количества передачи информации при допустимом уровне качества с учетом габаритно-весовых ограничений БПЛА, представляет собой сложную задачу, которая требует проведения тщательных исследований и практических испытаний в различных условиях.

Таким образом, указанные обстоятельства предопределяют выбор темы данной статьи, а также подтверждают ее актуальность, теоретическую и практическую значимость.

Анализ характеристик радиоканала связи с беспилотным летательным аппаратом проводился такими учеными как Слесарь В.И., Боев Н.Н., Шаршавин П.В., Barnard J., Bianchi L., Battaini C. Исследованию влияния доплеровского сдвига частоты и результата действия многолучевого распространения на канал связи с БПЛА посвятили свои труды Richard V.N., Prasad R., Austin R., Daigle, John N., Li, Lei.

Вопросами обеспечения помехозащищенности каналов управления БПЛА за счет использования различных типов антенных систем (многосекционные антенные решетки, секторные антенны и антенны на поворотных устройствах) занимаются такие отечественные и зарубежные авторы как Бухалёв В.А., Болдинов В.А., Сухачев А. Б., Golightly, David, Hu, Zhiqun, Zhang, Kun, Daigle.

Итак, анализ имеющихся на сегодняшний день публикаций свидетельствует о большом интересе к вопросам построения каналов управления и информационного обмена малогабаритных БПЛА со стороны как гражданских, так и военных специалистов. Однако, большинство публикаций на эту тему носит общий характер. В то же время, учитывая увеличение доли малогабаритных БПЛА всех классов, очевидно, что требует отдельного внимания рассмотрение особенностей их разработки и управления ими.
Принимая во внимание указанное, цель статьи можно сформулировать следующим образом - рассмотреть особенности и принципы построения канала управления и телеметрии, а также информационного канала системы приема и передачи данных малогабаритных БПЛА.

Основные требования к радиолинии управления и телеметрии заключаются в обеспечении высокой скрытности и помехозащищенности передачи данных. Это является следствием функционального назначения подсистемы системы приема и передачи данных, поскольку она непосредственно определяет живучесть комплекса оптической разведки и его способность функционировать в условиях интенсивного радиоэлектронного противодействия и попыток перехвата (подавления) управления.

Линии связи БПЛА - наземная станция управления (НСУ) как правило обеспечивают двустороннюю связь. Требования к телекоммуникационным линиям радиосвязи с БПЛА приведены в таблице 1.

В тоже время целесообразно выделить специфические, именно для малогабаритных БПЛА, требования к каналам управления:

- минимальные задержки в канале управления (работа в режиме реального времени);

- симметричная работа канала управления;

- возможность работы в сложных помеховых условиях;

- адаптация канала управления по скорости обмена информацией между НСУ и БПЛА,

- эффективное использование спектра сигнала и выходной мощности;

- низкое энергопотребление для повышения автономности работы БПЛА;

- вероятность битовой ошибки не должна превышать показателя $10^{-6}$.

Анализ перечисленных специфических требований показывает, что практическая реализация помехозащищенных канала управления малогабаритным БПЛА 


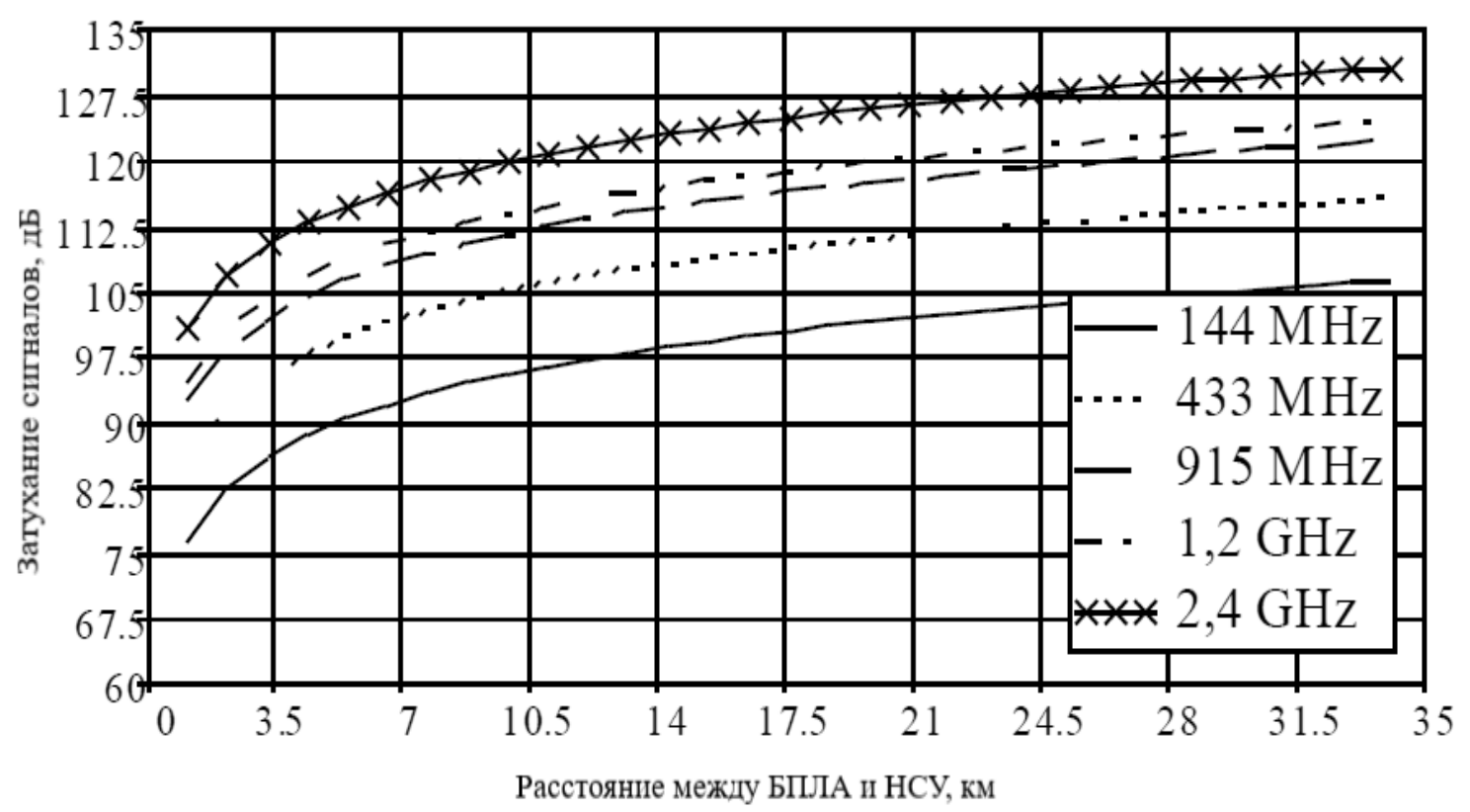

Рис. 1. Зависимость потерь на различных частотах от расстояния между БПЛА и НСУ

невозможна на базе известных протоколов, таких как Bluetooth, Wi-Fi, WiMAX и др. Основными их недостатками является низкая энергетическая эффективность и помехозащищенность.

Важной задачей при проектировании помехозащищенного канала управления малогабаритным БПЛА является выбор диапазона рабочих частот.

Известно, что основные потери при распространении радиосигналов (потери в свободном пространстве), рассчитываются следующим образом [3]:

$$
F S L=10 \lg \left(\frac{4 \pi d f}{c}\right)^{2}
$$

где $d$ - расстояние между БПЛА и НСУ; $f$ - частота сигнала; $c$ - скорость света.

На рис. 1 представлены зависимости основных потерь от расстояния между НСУ и БПЛА для различных значений рабочей частоты канала управления. В реальных условиях потери на трассе распространения сигнала будут больше за счет рельефа местности и различных предметов (сооружений). Для их учета целесообразно использовать рекомендации ITU-R, в частности P.1546 и P.528.

При энергетической оценке различных технологий и видов модуляции сигналов следует руководствоваться критериями энергетической эффективности и спек- тральной плотности мощности сигналов (СПМ). Причем энергетическая эффективность определяется как энергия, которую необходимо затратить на передачу одного бита информации с заданной достоверностью (вероятностью битовой ошибки), а СПМ рассчитывается как сосредоточение мощности сигнала на один интервал частоты, который обеспечивает передачу информации на заданных скоростях.

Вероятность битовой ошибки $(B E R)$ в общем случае зависит от соотношения сигнал/шум $\left(E_{b} / N_{0}\right)$ :

$$
B E R=f\left(\frac{E_{b}}{N_{0}}\right)
$$

где $E_{b}$ - энергия, затрачиваемая для передачи одного бита информации;

$N_{0}$ - спектральная плотность мощности белого шума в канале.

Одним из важнейших показателей качества канала управления БПЛА является зависимость вероятности появления ложного бита $P_{b}$ от $E_{b} / N_{0}$. Разница между реальным (принятым) и необходимым отношением $E_{b} / N_{0}$ дает энергетический резерв линии связи (или бюджет канала связи).

$$
M(\text { дБ })=\left(\frac{E_{b}}{N_{0}}\right)_{\text {прин }}(\text { дБ })-\left(\frac{E_{b}}{N_{0}}\right)_{\text {необх }}
$$

Мощность принимаемого антенной сигнала определяется по следующему выражению: 
Таблица 2. Анализ бюджета канала связи от БПЛА к НСУ

\begin{tabular}{|l|l|l|}
\hline & Усиление/ослабление дБм & Всего дБм \\
\hline Выходная мощность передатчика & +30 дБм & +30 \\
\hline Потери в фидерах и разъемах БПЛА & $-1,5$ дБ & $+28,5$ \\
\hline Усиление антенны БПЛА & +10 дБи & $+38,5$ \\
\hline Потери при распространении (2,4 ГГц на 150 км) & -145 дБ & $-106,5$ \\
\hline Усиление антенны НСУ & +30 дБи & $-76,5$ \\
\hline Потери в фидерах и разъемах НСУ & $-1,5$ дБ & -78 \\
\hline Уровень шума на входе приемника (полоса 20 МГц) & -100 дБ \\
\hline Отношение сигнал / шум & +22 дБ & \\
\hline
\end{tabular}

$$
\begin{aligned}
& P_{R}(\text { дБ })=P_{T}(\text { дБ })+G_{R}(\text { дБ })+G_{T}(\text { дБ })- \\
& -L_{s}(\text { дБ })-L_{0}(\text { дБ })
\end{aligned}
$$

где $G_{R}$ и $G_{T}-$ коэффициенты усиления передающей и приемной антенн;

$P_{T}$ - передаваемая мощность;

$L_{s}$ - коэффициент потерь системы, связанных с распространением;

$L_{0}$ - коэффициент потерь системы, не связанных с распространением (потери в фидере и разъемах НСУ и БПЛА.

Из выше представленных уравнений получаем следующее:

$$
\begin{aligned}
& M(\text { дБ })=P_{T}(\text { дБм })+G_{R}(\text { ББ })+G_{T}(\text { дБ })- \\
& -L_{S}(\text { дБ })-P_{s}(\text { дБм })
\end{aligned}
$$

где $P_{s}$ - чувствительность приемника, дБм.

При работе БПЛА в пределах прямой видимости с НСУ диапазон изменений уровня сигнала через замирание может достигать 15 дБ. Энергетический запас М используется для компенсации этих замираний.

Для характеристики достоверности связи в управляющем канале можно использовать два показателя: коэффициент ошибок (вероятность ошибки при передаче единицы информации) и отношение сигнал-шум $h_{n}$ (отношение энергии символа (бита) к спектральной плотности шума) на выходе корреляционного (согласованного) приемника:

$$
h_{n}=\frac{P_{C_{1}}}{P_{\mathrm{w}_{0}}}+P_{\mathrm{w}_{1}}+\mathrm{P}_{3_{1}}
$$

где $P_{C l}-$ мощность сигнала на выходе приемника;

$P_{\text {шо }}$ - мощность внутренних шумов на выходе приемника;

$P_{\text {ш1 }}$ - мощность внешних широкополосных помех;

$P_{31}$ - мощность узкополосных помех.
Из анализа выше представленного можно сделать вывод о том, что мощность сигнала и полоса частот являются основными ресурсами системы связи. Эти ресурсы тратятся на передачу информации. Эффективность расходования ресурсов характеризуется показателями энергетической и частотной эффективности:

$$
\beta=\frac{R \cdot N_{0}}{P_{c}},\left(\gamma=\frac{R}{F}\right)
$$

При этом предельная зависимость, которая определяет взаимосвязь параметров эффективности, имеет следующий вид:

$$
\beta=\gamma /\left(2^{\gamma}-1\right)
$$

Как видно из таблицы 2, для обеспечения энергетической эффективности канала связи при большом затухания сигнала на трассе необходимо использовать направленные антенны на борту БПЛА.

Задача управления направлением максимального усиления бортовой антенны может быть решена несколькими способами:

1. Использование многоэлементной антенной решетки с управляемой диаграммой направленности.

2. Использование нескольких переключающих антенн.

3. Установка антенны на опорно-поворотном устройстве.

Итак, принимая во внимание вышеизложенное, можно отметить, что если скорость передачи информации $R$ задана, то при работе с низким отношением сигнал/шум для помехозащищенных систем связи необходимо уменьшать частотную и энергетическую эффективность.

В отличие от канала управления, информационный канал, наоборот, невозможно реализовать без достижения высоких показателей удельных частотных и энергетических затрат. Это вызвано большим 
объемом данных, передаваемых в условиях жесткого частотно-временного и энергетического ресурсов системы разведки. Принципиальным вопросом данного анализа является выбор аналогового или цифрового способа передачи данных.

В малогабаритных БПЛА теоретически возможно применение принципов как аналоговой, так и цифровой передачи данных. Но, по мнению автора, цифровой способ передачи данных имеет неоспоримые преимущества, к числу которых относятся:

- высокое качество цифрового изображения, которое достигается устранением характерных для аналоговых методов помех с помощью цифровых методов повышения помехоустойчивости сигналов;

- возможностью гибкой адаптации качества по командам оператора БПЛА;

- большая эффективность использования спектрального диапазона;

- возможность скрытной передачи информации;

- пригодность полученных кадров изображений для программной обработки и архивации в базах данных;

- современное состояние интегральной элементной базы, что позволяет применять модульный принцип реализации различных вариантов цифровых систем;
- возможность варьирования количеством передачи данных в единицу времени в пользу повышения качества (достоверности) передачи и др.

Основой для создания протокола и технических средств цифровой оптико-электронной разведки для малогабаритных БПЛА с учетом их специфических характеристик может быть европейский стандарт цифрового телевидения DVB-T2, предполагающий использование принципа OFDM передачи. Метод OFDM передачи позволяет компенсировать эффект Допплера не только путем внесения опережающих частотных сдвигов при формировании сигналов в передатчике радиолинии, но и на этапе обработки принятых сигналов. Учет доплеровских смещений при этом может осуществляться, как для всего пакета, так и для каждой поднесущей частоты отдельно.

Таким образом, подводя итоги, отметим, что организацию канала управления и телеметрии малогабаритным БПЛА целесообразно проводить путем использования сигналов с прямым расширением спектра за счет замены простых элементарных сигналов переносчиками с псевдошумовой структурой. Для информационного канала системы приема и передачи данных наиболее приемлемым являются цифровые методы, предполагающие использование алгоритма формирования цифрового сигнала формата DVB-T2.

\section{ЛИТЕРАТУРА}

1. Daigle, John N. User Association and Power Control for UAV-Enabled Cellular Networks // IEEE wireless communications letters. 2020. Volume 9: Number 3; pp 267-270.

2. Li, Lei UAV Positioning and Power Control for Two-Way Wireless Relaying // IEEE transactions on wireless communications. 2020. Volume 19: Number 2; pp 10081024.

3. Попов А. Р. Методология построения каналов радиосвязи с шумоподобными сигналами для управления беспилотным летательным аппаратом // Наноиндустрия. 2020. № S96-1. С. 28-30. 